\title{
FINITE ELEMENT MODELING OF THE AP1000 NUCLEAR ISLAND FOR SEISMIC ANALYSES AT GENERIC SOIL AND ROCK SITES
}

\author{
Richard S. Orr \\ Westinghouse Electric Company \\ PO Box 355 \\ Pittsburgh, Pennsylvania, USA 15230 \\ Phone: 412-374-5924, Fax: 412-374-5005 \\ E-mail: orrrs@westinghouse.com
}

\author{
Leonardo Tunon-Sanjur \\ Westinghouse Electric Company \\ PO Box 355 \\ Pittsburgh, Pennsylvania, USA 15230 \\ Phone: 412-374-5924, Fax: 412-374-5005 \\ E-mail: tunonsli@westinghouse.com
}

\author{
Sener Tinic \\ Nordostschweizerische Kraftwerke AG \\ Parkstrasse 23 \\ 5400 Baden, Switzerland \\ Phone: +41 5620035 29, Fax: +41 562003754 \\ E-mail: sener.tinic@nok.ch
}

\section{ABSTRACT}

The AP1000 is a standard design developed by Westinghouse and its partners for an advanced nuclear power plant utilizing passive safety features. The design has been certified by the US Nuclear Regulatory Commission based on their review of seismic analyses at hard rock sites. The plant has five principal building structures; the nuclear island, the turbine building; the annex building; the diesel generator building and the radwaste building. The nuclear island consists of the containment building (the steel containment vessel and the containment internal structures), the shield building, and the auxiliary building. These structures are founded on a common basemat and are collectively known as the nuclear island. This paper describes shell and stick finite element models used in fixed base dynamic analyses for the hard rock design certification using the general purpose finite element program ANSYS. It describes a coarser shell model developed for use in soil structure interaction (SSI) analyses. This model is developed in both ANSYS and the soil structure interaction (SSI) program SASSI. Results of the three types of models from ANSYS analyses are compared for a hard rock site. Results are also compared between the ANSYS and SASSI analyses for the same model.

\section{KEYWORDS}

AP1000, Westinghouse, Nuclear Island, Power Plant, Seismic Analysis, Structural Analysis, Structural Design, Solid Model, FE-Model, Stick Model, ANSYS, SASSI 


\section{INTRODUCTION}

The AP1000 is a standard design developed by Westinghouse and its partners for an advanced nuclear power plant utilizing passive safety features. The design has been certified by the US Nuclear Regulatory Commission based on their review of seismic analyses at hard rock sites. The plant has five principal building structures; the nuclear island, the turbine building; the annex building; the diesel generator building and the radwaste building (Figure 1). The nuclear island consists of the containment building (the steel containment vessel and the containment internal structures), the shield building, and the auxiliary building. These structures are founded on a common basemat and are collectively known as the nuclear island (Figure 2).

The seismic analyses performed for the AP1000 design certification on hard rock used the general purpose finite element program ANSYS (Reference 1). The models used in these analyses are described in Reference 3. Westinghouse is now extending the applicability of the design to soil sites. New analyses are being performed using the soil structure interaction (SSI) program SASSI (Reference 2). Results of all soil cases are enveloped in the structural analyses and qualification of the AP1000 nuclear island buildings for application at soil and rock sites.

\section{SEISMIC ANALYSES FINITE ELEMENT MODELS}

The AP1000 seismic analyses for the hard rock design certification analyses used two distinct models. A third model has been developed for the analyses at soil sites. The detailed finite element model shown in Figure 5 was used to develop the properties of the nuclear island stick model; both models were used to obtain the nuclear island seismic response for hard rock sites. The coarse finite element model shown in Figure $\mathbf{6}$ has been developed to obtain the nuclear island seismic response for soft soil to firm rock sites.

\section{Lumped Mass Stick Model}

Three-dimensional, lumped-mass stick models were developed to represent the steel containment vessel, the containment internal structures, and the coupled shield and auxiliary buildings. Figure 3 shows the stick model for the auxiliary and shield building. Discrete mass points are provided at major floor elevations and at locations of structural discontinuities. The structural eccentricities between centers of rigidity and the centers of mass of the structures are considered. These seismic models consist of lumped masses connected to vertical elastic structural elements by horizontal stiff beam elements to simulate eccentricity. The individual building lumped-mass stick models are interconnected with other stiff beam elements to form the overall dynamic model of the nuclear island.

Seismic subsystems coupled to the overall dynamic model of the nuclear island include the coupling of the reactor coolant loop model (Figure 4) to the model of the containment internal structures, and the coupling of the polar crane model to the model of the steel containment vessel. The total mass of other major subsystems and equipment is less than one percent of the respective supporting nuclear island structures; therefore, the mass of other major subsystems and equipment is included as concentrated lumped-mass only.

Because of the irregular structural configuration, the properties of the three-dimensional, lumped-mass stick models were determined using building sections extracted from the three-dimensional building finite element models. The properties of the stick model beam elements, including the location of centroid, center of rigidity and center of mass, and equivalent sectional areas and moment of inertia, were computed using specific finite element sections representing the walls and columns between principal floor elevations of the structures. The equivalent translation and rotational stiffness (sectional areas and moment of inertia) of the three-dimensional beams were computed by applying unit forces and moments at the top of the specific finite element sections. 
The lumped mass stick model was a valuable tool in the early stages of the AP1000 seismic analyses as it provided relatively quick and clear insights of the important modes of the structure and seismic interaction between the nuclear island structures. The lumped mass stick model was also used to establish the key parameters in the soil structure interaction analyses, such as depth to bedrock, Poisson's ratio, and the critical soil conditions. The lumped mass model was also used to establish the loads for the AP1000 overturning analyses.

\section{Finite Element Shell Model used for Hard Rock (NI10)}

Acceleration response spectra have been traditionally developed by a dynamic analysis of Stick Models. The stick models have been carefully prepared so that the responses at lumped mass nodes simulate the structural response as well as possible. The development of stick model properties has often been aided by the use of shell and/or solid models. With the advent of more powerful computers, and more efficient computer codes such as ANSYS (Reference 1) it is now possible to develop acceleration response spectra for complex structures, such as the AP1000 nuclear island, directly from large solid-shell models. Comparisons between the stick and shell model are included in Reference 3.

The large solid-shell finite element model of the AP1000 nuclear island (Figure 5) is comprised of the auxiliary and shield building (ASB) shell model, and the containment internal structure (CIS) solid-shell model. The major equipment supported by the CIS are represented by stick models and are connected to the CIS. These stick models are the Steel Containment Vessel (SCV) and the polar crane models, the reactor coolant loop (RCL) model, and the pressurizer (PZR) model. This model is designated NI10 since the nominal shell element dimension in the auxiliary building is about 10 feet. The time history analyses of the nuclear island shell model were performed in two analyses. One analysis used the finite element model of the ASB and a superelement of the CIS and major components, the other analysis used the finite element model of the CIS and major components and a superelement of the ASB.

The Hard Rock model analyses are very time consuming but this more detailed model provides accurate information in the high frequency region and the additional detail in the model allows modeling of the equipment support location and wall and beam eccentricities in a more precise way. The Hard Rock model is also used as a benchmark for the lumped mass model and the soil structure interaction model. Modal analyses results of the lumped mass stick model and the soil structure interaction model were compared to those of the detailed Hard Rock model and found to be acceptable.

\section{Soil Structure Interaction (SSI) Model used for Stiff Rock to Soft Soil (NI20)}

The model shown in Figure 6 to be used in the three-dimensional soil-structure interaction analyses has been set up in both ANSYS and SASSI. It has fewer nodes and elements than the NI10 model used for the hard rock analysis but it captures the essential features of the nuclear island configuration. This model is designated NI20 since the nominal shell and solid element dimension is about 20 feet.

Time history analyses are performed in ANSYS with the underside of the basemat fixed and no consideration of side soil. This is the same assumption as used in the models previously described and used for the design certification hard rock analyses. Similar analyses are performed for the model in SASSI. This provides a check of the three ANSYS models as well as the SASSI model.

The soil-structure interaction analyses of the nuclear island are performed using the program SASSI, which is capable of handling two- and three-dimensional soil-structure interaction problems involving multiple structures with rigid or flexible embedded foundations of arbitrary shape. The analyses are performed using the complex frequency-response method. Computer program SHAKE (Reference 4) is used to compute the safe shutdown earthquake dynamic strain compatible soil properties, such as shear modulus and damping. The material (hysteretic) damping ratio for soil in the soil-structure interaction analyses is limited not to exceed 15 percent. 


\section{SEISMIC ANALYSES RESULTS}

The stick, Hard Rock (NI10), and SSI (NI20) models are all intended to represent the nuclear island structures. Acceleration response spectra from the three ANSYS models are shown in Figures 7 to 11 . The nuclear island locations where the comparisons are made are the top of the shield building roof, the northeast corner of the auxiliary building roof, the interface of the CIS and shield building cylindrical wall, and the top of the pressurizer compartment in the CIS. Figure 10 includes results from three soil cases that were considered in the AP1000 seismic analyses. All other figures compare the models using the hard rock conditions only.

\section{Top of the shield building}

The comparisons are very good for the response spectra in both horizontal directions. The vertical floor response spectra compare very well for the SSI and Fine Hard Rock model. The vertical floor response spectra compare well for frequencies below $5 \mathrm{~Hz}$ but not as well at higher frequencies. This difference occurs because the shell model results are at the edge of the building and the stick model results are at the center of mass. The comparison is better when the effect of rotation of the stick model is extrapolated to the edge of the building.

Northeast corner of the Auxiliary Building roof:

The horizontal response spectra in the X (NS) direction of the comparisons show highest spectra for the stick model, and the lowest for the fine model. The other horizontal direction Y (EW) shows good comparisons except for a high peak observed only in the SSI model around $13 \mathrm{~Hz}$. The results of the SSI model are conservative at frequencies greater than $10 \mathrm{~Hz}$. The high frequencies modes will not be excited at soil sites since the soil attenuates the high frequencies.

The vertical floor response spectra for the auxiliary building compare well for frequencies below $9 \mathrm{~Hz}$ but they do not compare as well at higher frequencies where the auxiliary building response is governed by local vertical modes of the structure at greater than $20 \mathrm{~Hz}$. In addition, the vertical response at 25 hertz in the SSI model is not considered accurate since the refinement of the model is insufficient to predict such frequencies.

\section{CIS and Shield Building cylindrical wall interface:}

The floor response spectra comparisons are very good for this node which is at a low elevation and has response closely matching the ground input. The slight differences are due to local modes which are represented better in the detailed model.

\section{Containment Internal Structures (CIS):}

The fundamental mode of the CIS is at about 12 hertz. Both the stick and SSI models show higher results than the fine model. Both shell models shows a local response of the east wall of the east steam generator compartment that is not well predicted by the stick models. The east wall of the east steam generator compartment responds independently of the rest of the structure. This local response is difficult to include in a stick model. The interaction between dominant local modes of the SG, the pressurizer compartment and the IRWST are important in the seismic response of the CIS but these cannot be captured by the stick model.

The SASSI program gives higher response than ANSYS at high frequencies as shown in Figure 11. The reason for this conservatism is the different formulation in the solid elements being used. Figure 10 also includes results from three soil cases that were considered in the AP1000 seismic analyses. This figure shows that the maximum response in the soil cases occurs below $10 \mathrm{~Hz}$ where the ANSYS and SASSI models give similar results. The conservatism at high frequencies in the SASSI analyses for hard 
rock does not result in excessive conservatism in the design because results for the hard rock case are extracted from the detailed ANSYS model.

Other observations that were obtained from the seismic analyses include:

- The steel containment vessel response spectra of the stick, SSI and Fine Hard Rock nodes show very similar responses.

- Except for the response at the centers of flexible walls and floors, most zero period acceleration (ZPA) responses at nodes of the shell model are similar to or less than those of the stick model. The ZPA given by the stick model represents the overall building responses reasonably well.

- The detailed shell model provides acceleration response spectra at the centers of flexible walls and floors; these locations need special consideration in analyses using stick models.

- The modal properties of models permit reasonable comparison of fundamental modes. The study has shown that development of floor response spectra at key nodes of models provides an excellent method to compare the dynamic properties over a much broader frequency range thus providing comparison of local higher frequency modes.

- Shell models are feasible with today's computer capability. The comparisons of the stick model against the shell models with two levels of refinement show that all three models give similar results in the 2-10 hertz frequency range. This is the frequency range that is important for seismic design. The higher frequency responses cannot be predicted as well by the less detailed stick and coarse shell model. Responses in these higher frequency ranges have been observed in earthquakes. However, they are not damaging since the maximum deflections are small and non-linearities can significantly reduce the response below that predicted in linear elastic analyses. Hence, stick models are adequate for seismic design of nuclear power plants. For complex unsymmetric structures great care is required to establish an appropriate multiple stick representation; this will include development of a shell model to justify the member properties. In many cases it will be easier to use this shell model directly in dynamic analyses rather than spend the effort required to justify the simpler stick model.

- Both the stick model and coarse finite element models can provide good results at soil sites where high frequency effects are attenuated by the soil. Such models can also be used for hard rock analyses if the engineer determines that accurate prediction of high frequency response is less important to the design. Where he needs high frequency response more detailed models are necessary. Typically he can consider local responses such as floor flexibility in separate local models or by including a single degree of freedom representation of the floor in the stick model.

\section{CONCLUSIONS}

The stick and shell seismic models have adequate level of detail to predict the responses in the frequency range of interest for seismic design. The AP1000 seismic analyses for sites from soft soil to hard rock have been efficiently performed using a combination of three models. The stick models were used to establish the important parameters that needed to be considered in soil structure interaction analyses and were also used to establish loads for overturning analysis. The coarse SSI model was used to develop the floor response spectra at soft soil to firm rock sites. The Hard Rock Fine model was used to develop the floor response spectra at hard rock sites and to develop loads for flexible walls and floors. 


\section{REFERENCES}

1) ANSYS User's Guide, ANSYS, Inc.

2) Lysmer, J., Ostadan, F., Chin, C. (1999), "SASSI2000- System for Analysis of Soil-Structure Interaction", University of California, Berkeley, California.

3) Finite Element Modeling of AP1000 Nuclear Island, Sener Tinic, Richard Orr, SMIRT17.

4) Schnabel, P. B.; Lysmer, J.; Seed, H. B. (1972), "SHAKE-A Computer Program for Earthquake Response Analysis of Horizontally Layered Sites," Report No. EERC 72-12, Earthquake Engineering Research Center, UCB, December. 


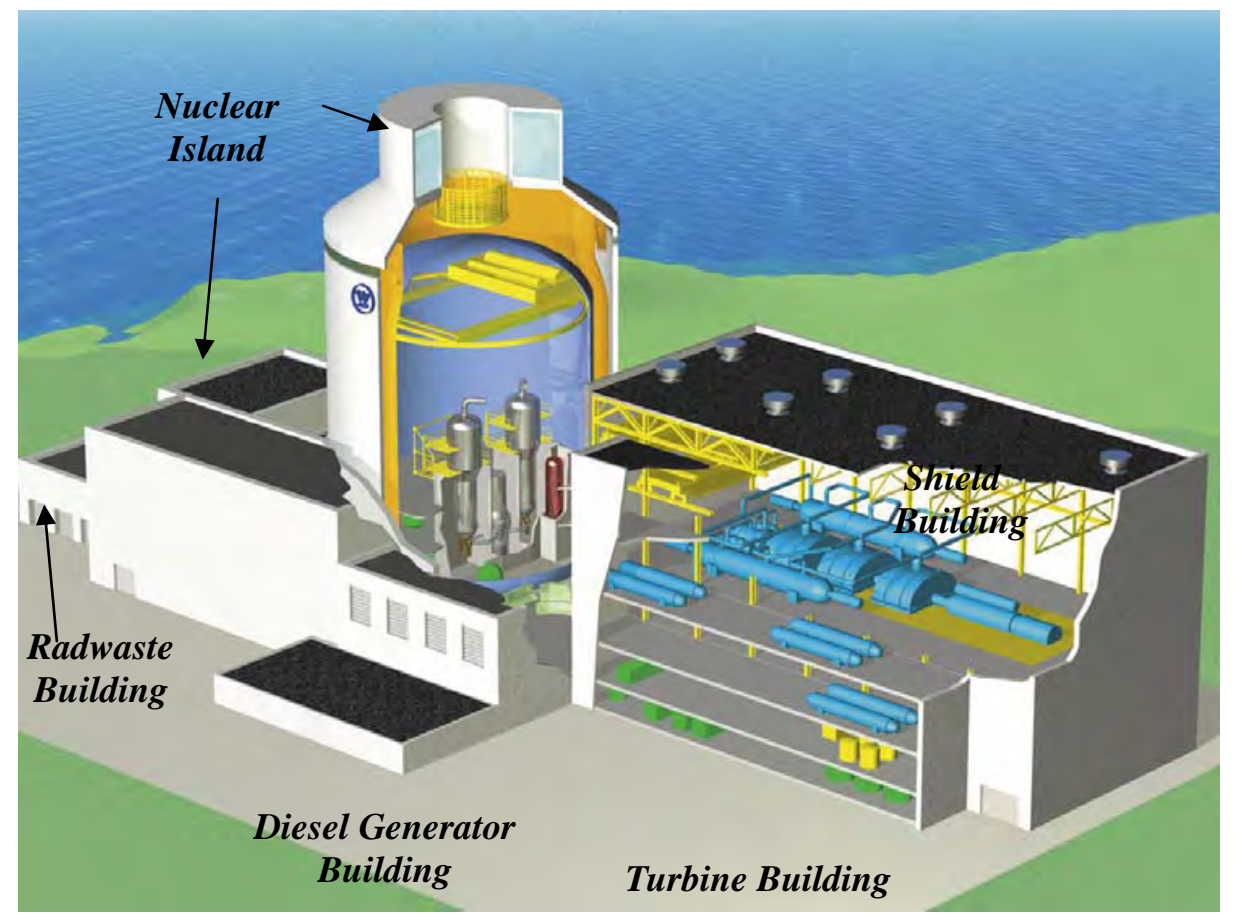

Figure 1: AP1000 Principal Building Structures

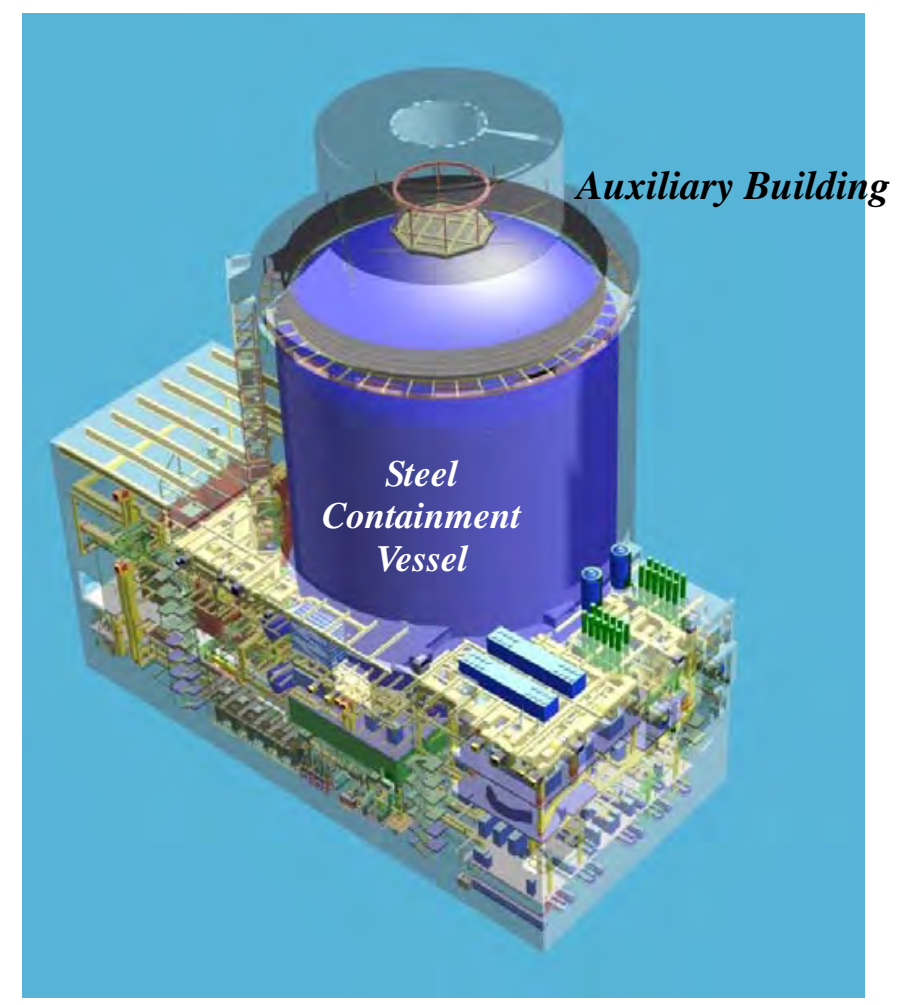

Figure 2: AP1000 Nuclear Island Structures and Common Basemat 


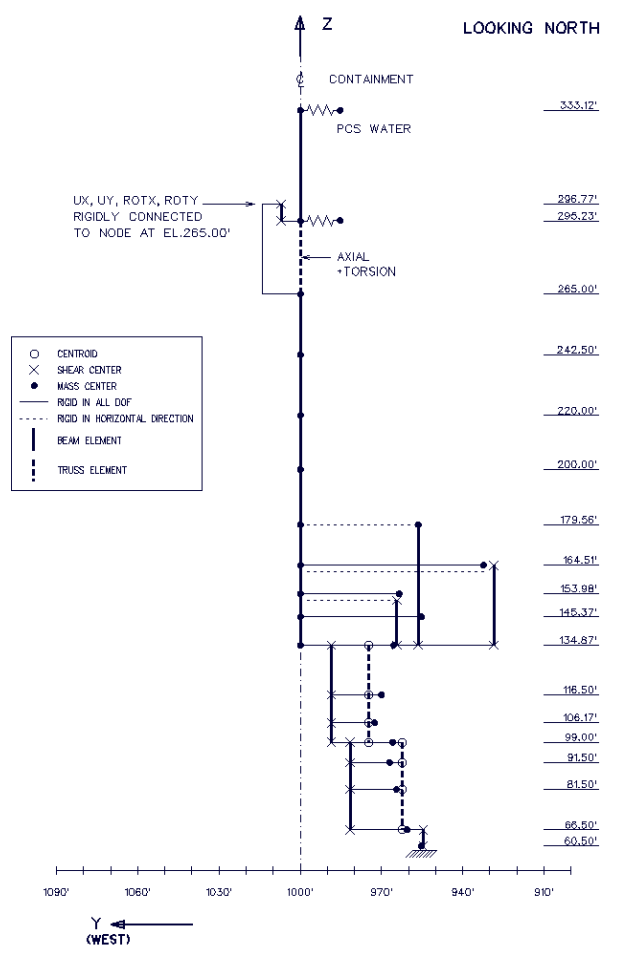

Figure 3: Nuclear Island Auxiliary and Shield Building Stick Model

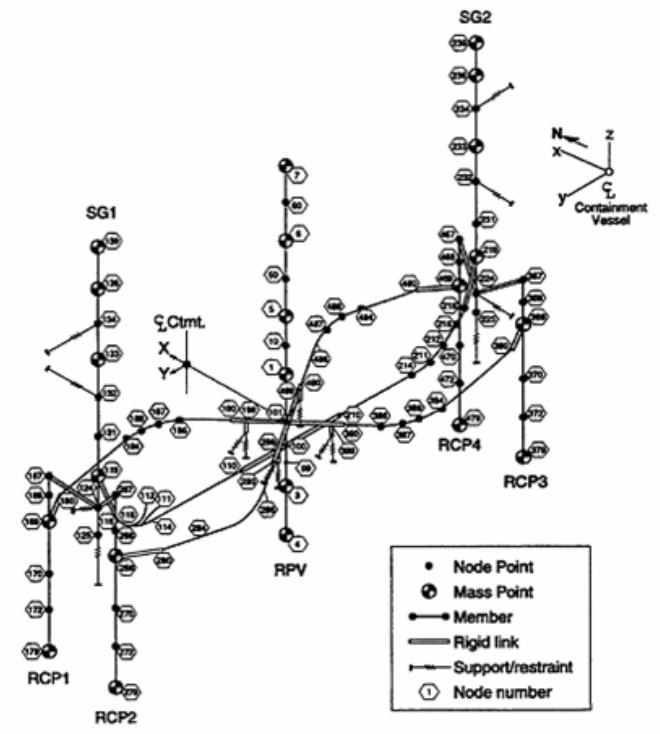

Figure 4: Reactor Coolant Loop Model 


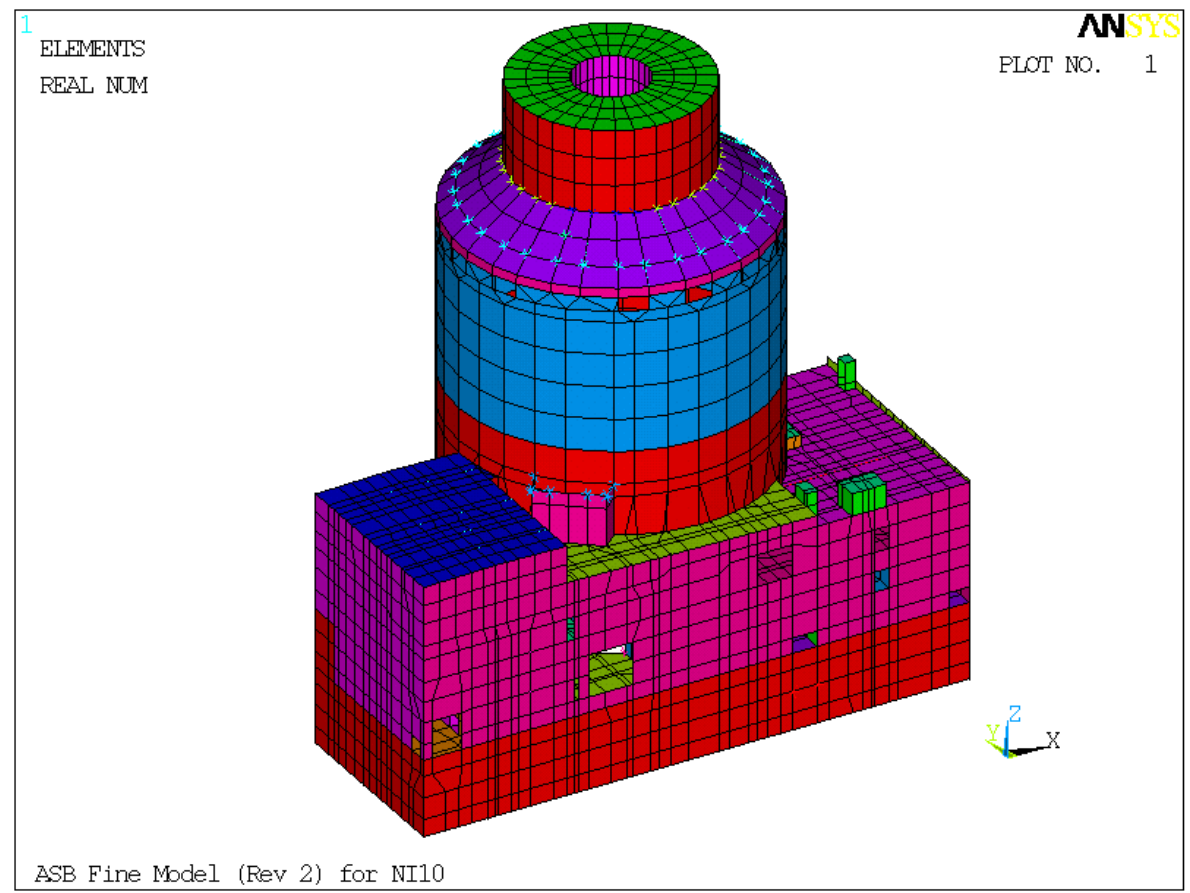

Figure 5: Nuclear Island Fine Model - ni10

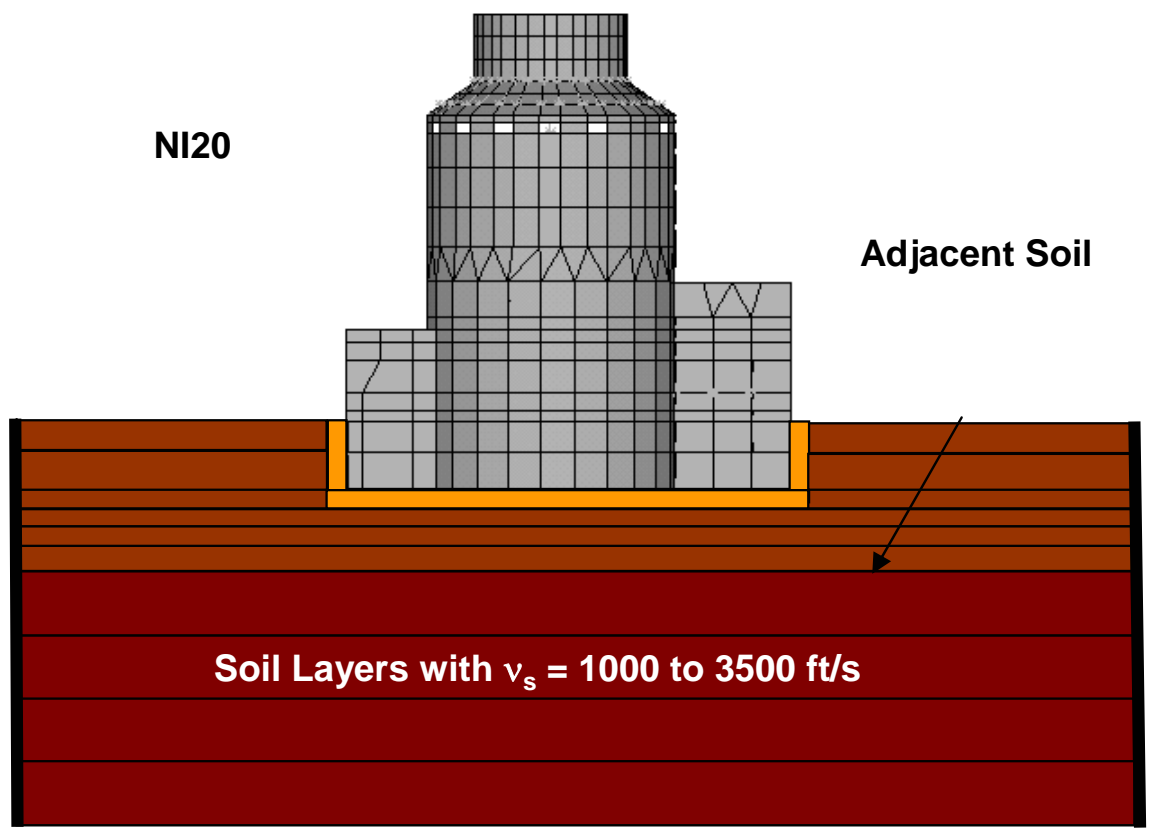

Figure 6: Soil Structure Interaction Model - ni20: Looking East 

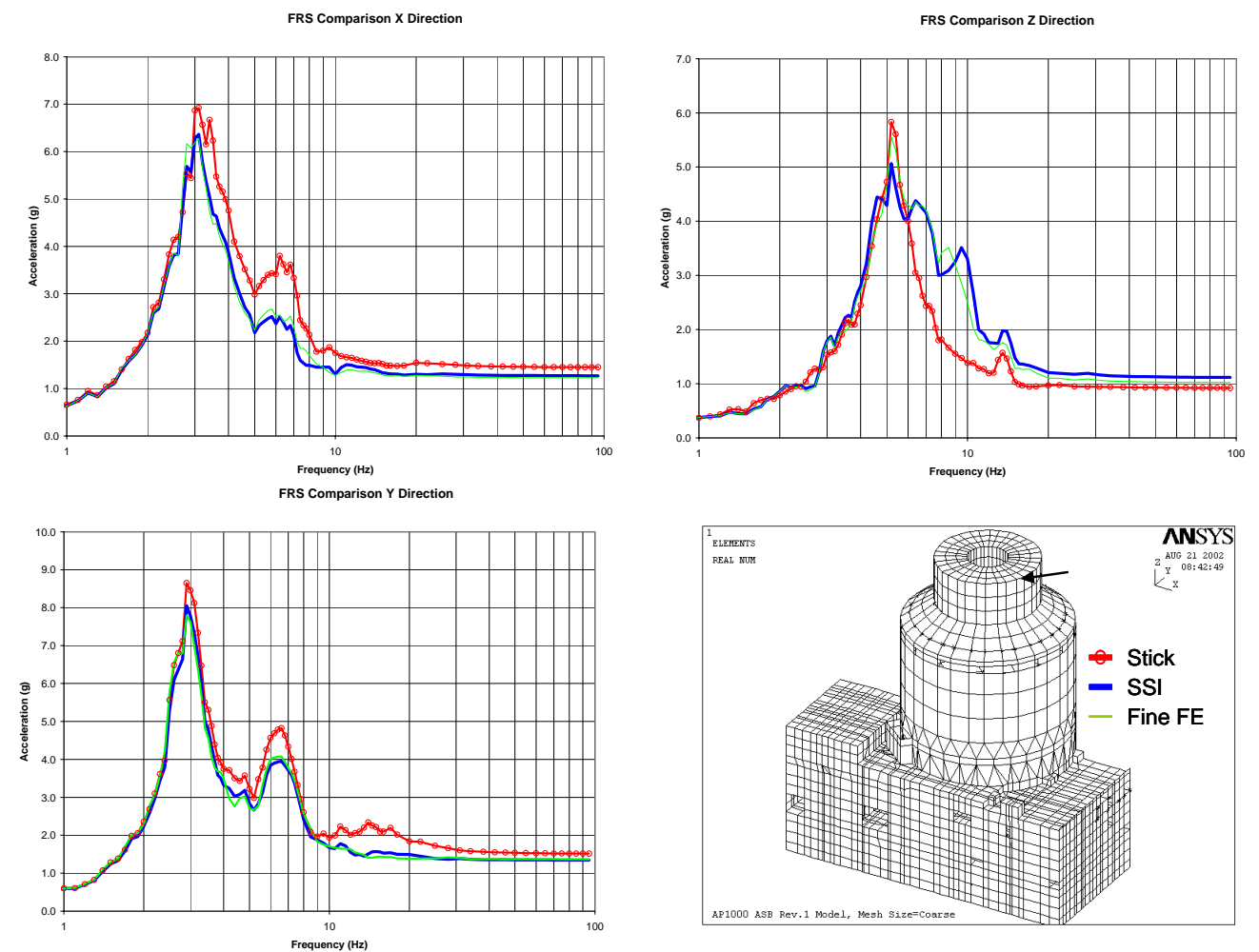

Figure 7: FRS results at Top of Shield Building

FRS Comparison X Direction

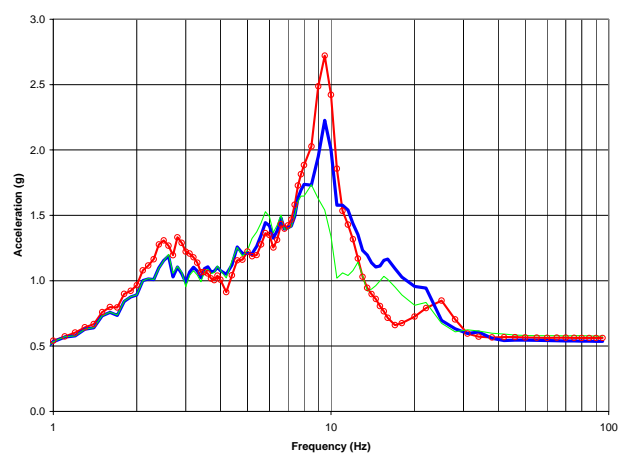

FRS Comparison Y Direction

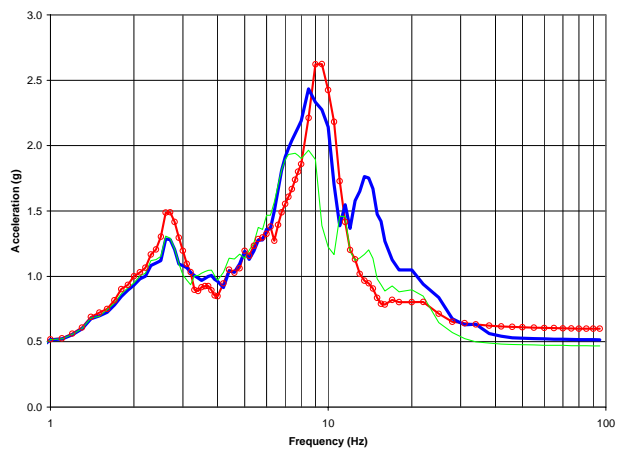

FRS Comparison Z Direction
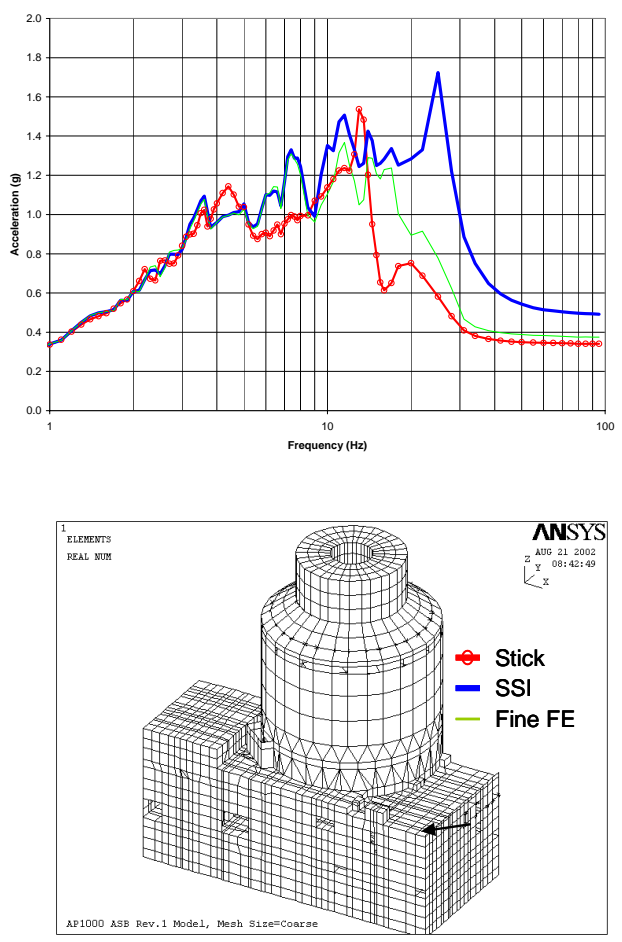

Figure 8: FRS results at Northeast corner of Auxiliary Building 
FRS Comparison $X$ Direction

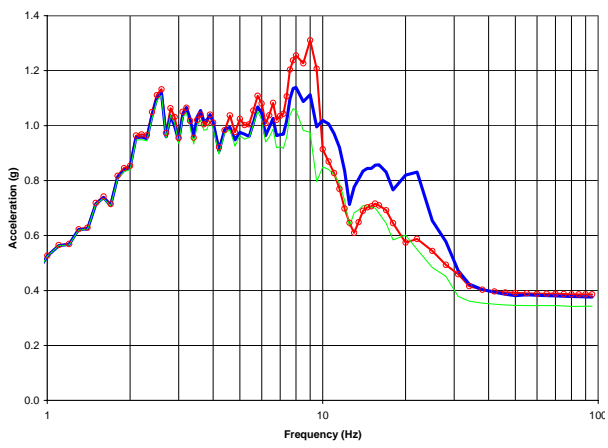

FRS Comparison $Y$ Direction

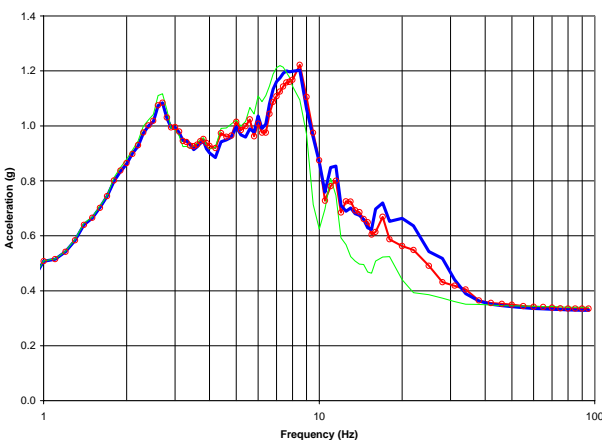

FRS Comparison Z Direction

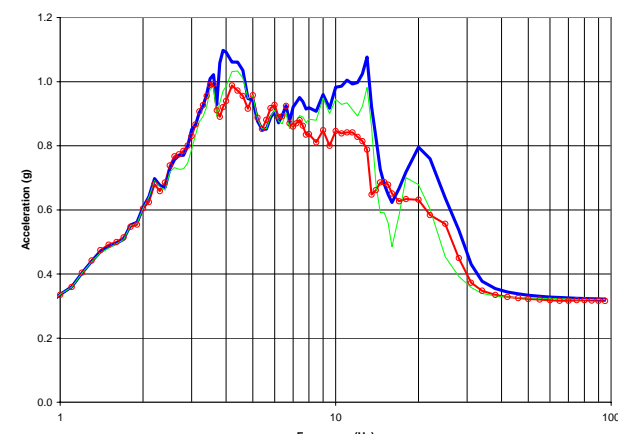

$\mathbf{N}$

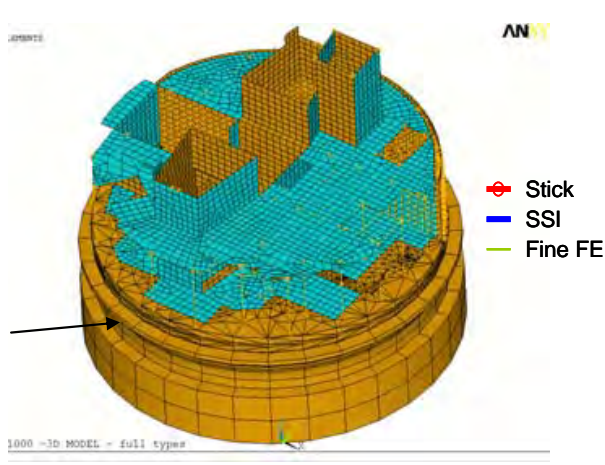

Figure 9: FRS results at CIS and Shield Building cylindrical wall interface
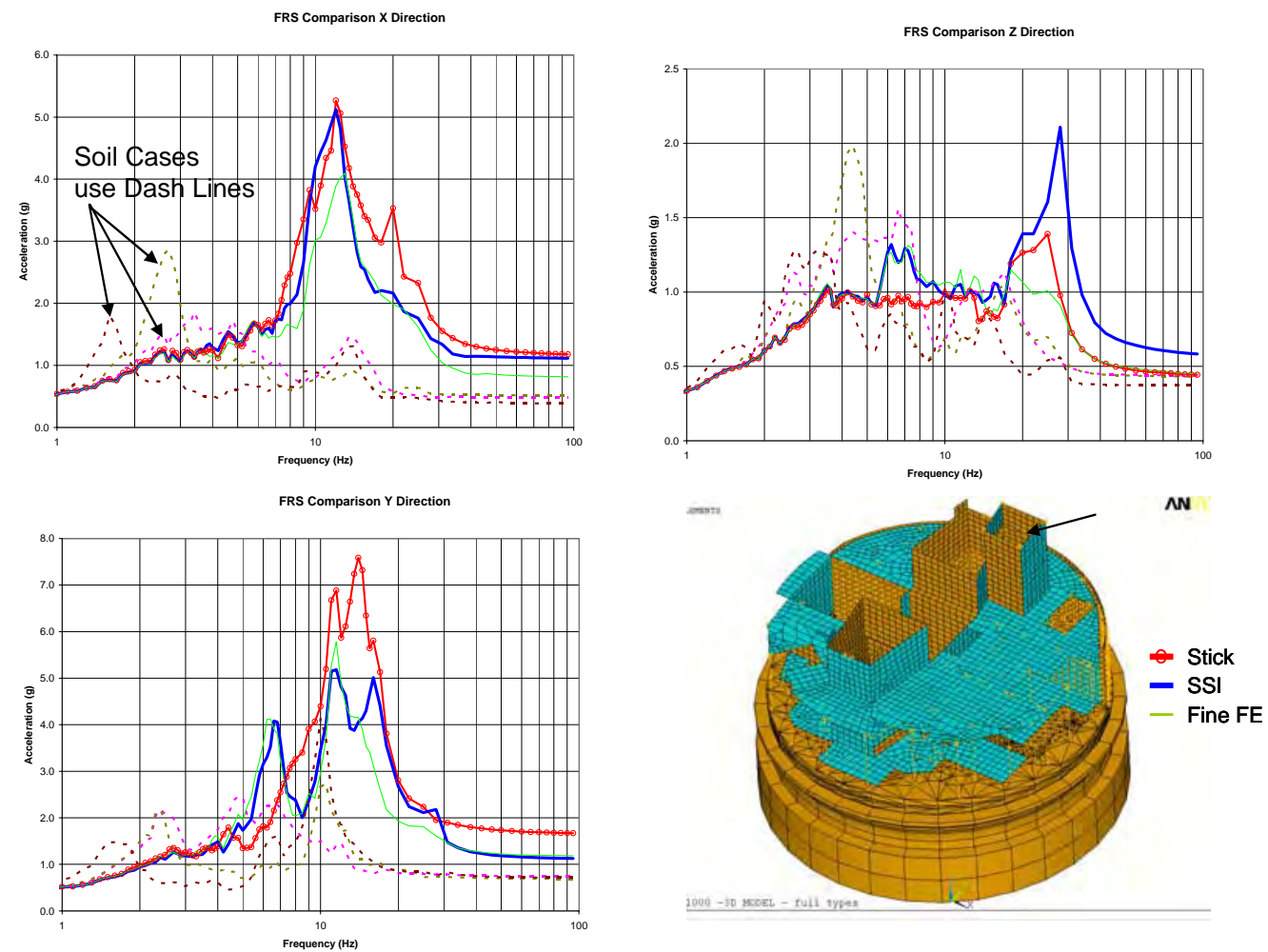

Figure 10: FRS results at Top of Pressurizer compartment 
FRS Comparison X Direction
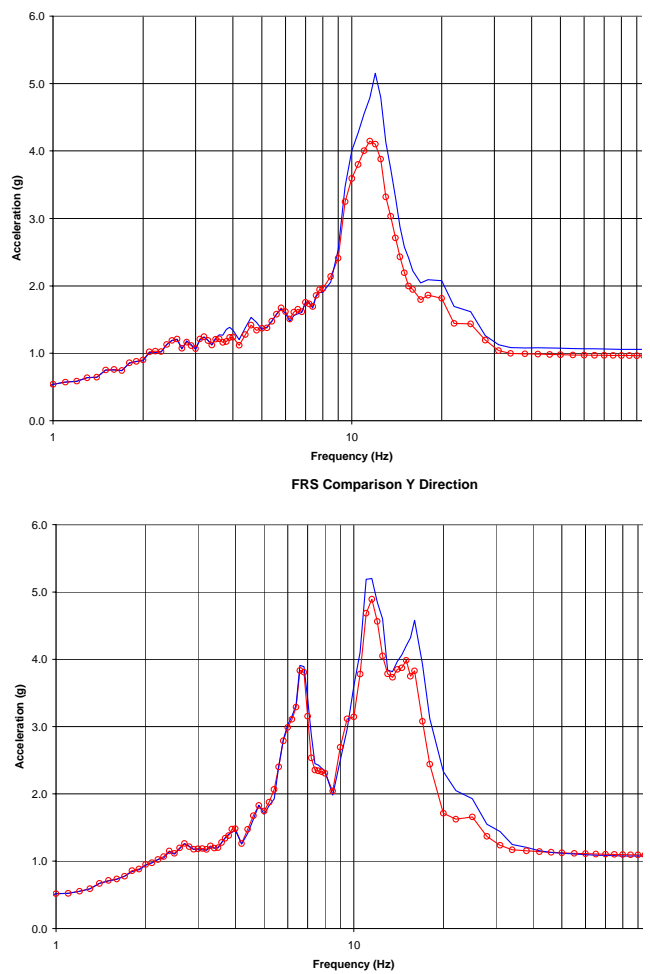

FRS Comparison Z Direction

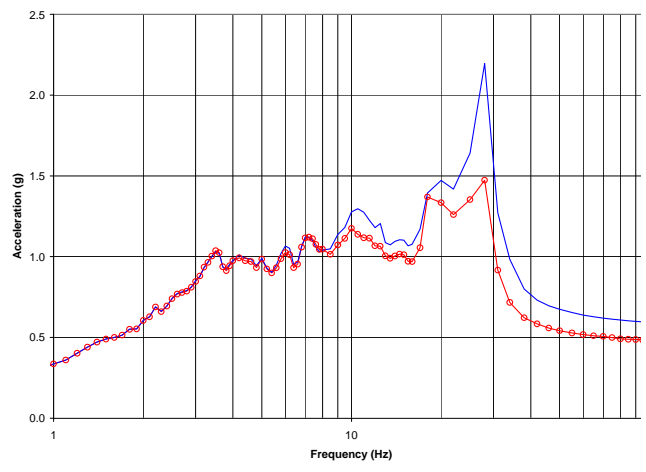

ELEMENTS
REAL NUM

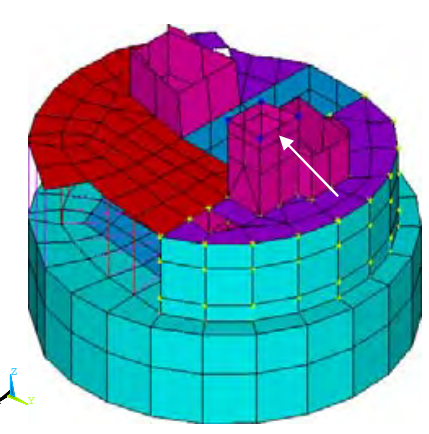

Iuv

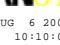

ANSYS ni20

- SASSI ni20

Figure 11: ANSYS vs SASSI FRS comparisons at Top of Pressurizer compartment 